\title{
Galactosemia in the Turkish population with a high frequency of Q188R mutation and distribution of Duarte-1 and Duarte-2 variations
}

\author{
Rıza Köksal Özgül ${ }^{1,2}$, Ayşegül Güzel-Ozantürk ${ }^{1,3}$, Halil Dündar ${ }^{1}$, Didem Yücel-Yılmaz ${ }^{1}$, Turgay Coşkun ${ }^{1}$, \\ Serap Sivri ${ }^{1}$, Sultan Aydoğdu ${ }^{4}$, Ayşegül Tokatlı ${ }^{1}$ and Ali Dursun ${ }^{1}$
}

Classical galactosemia is an inherited recessive disorder of galactose metabolism caused by deficiency of the enzyme galactose1-phosphate uridyl transferase (GALT), which is caused by mutations in the GALT gene. In this study, 56 Turkish patients diagnosed with galactosemia were screened for GALT gene mutations using Affymetrix resequencing microarrays. Eleven types of mutations were detected in these patients, including two novel mutations (R258G and G310fsX49) and nine recurrent mutations. We detected six patients who were homozygous for the E340* mutation and for N314D, L218L silent substitutions (Duarte-1 variant) in this study. The haplotype E340*, N314D and L218L has been reported only in Turkish patients, which suggests that the E340* mutation is specific for our population and might be spread by a Turk ancestor. In patients, the Duarte-1 allele was found with a frequency of $10.71 \%$, whereas the Duarte-2 allele was not detected. Duarte-1 and Duarte-2 alleles were found to be present at a frequency of $2.3 \%$ and $1.4 \%$, respectively, in the screening of 105 healthy individuals. Considering all detected mutations, it is a very important finding that exons 6 and 10 of the GALT gene account for $79 \%$ of all mutant alleles in the Turkish population. The most common mutation is Q188R, with a frequency of $55.35 \%$. Journal of Human Genetics (2013) 58, 675-678; doi:10.1038/jhg.2013.76; published online 8 August 2013

Keywords: Duarte alleles; galactosemia; GALT; microarray resequencing; mutation screening

\section{INTRODUCTION}

Galactosemia is an autosomal recessive disorder of galactose metabolism resulting from deficient or absent activities of galactokinase, galactose-1-phosphate uridyl transferase (GALT) and UDP-galactose $4^{\prime}$-epimerase enzymes, which have a role in the Leloir pathway of galactose metabolism. ${ }^{1}$ The predominant form is classic-type galactosemia, which is due to a severe reduction or absence of the GALT enzyme, and has an incidence of 1/40 000-60 000 in European newborns. ${ }^{2}$ More than 150 mutations in the GALT gene have been reported. ${ }^{3}$

The decrease in GALT enzyme activity results in an accumulation of gal-1P in different organs. The disease usually appears during the initial days of life after ingestion of breast milk or formula. The earliest clinical findings of the disease are vomiting, diarrhea, failure to thrive and jaundice. Although many of these symptoms disappear with a galactose-restricted diet, long-term complications such as mental retardation, speech or learning difficulties and premature ovarian failure in female patients may still ocur. ${ }^{4}$

Type I galactosemia is classified into severe classical and mild Duarte phenotypes on the basis of residual GALT activity. Classical galactosemia is frequently associated with S135L, Q188R and K285N mutations in the GALT gene. The functionally neutral N314D variation in the GALT gene is associated with Duarte galactosemia and is widespread among populations across the world. The Duarte-1 variant has normal or increased GALT enzyme activity, whereas the Duarte- 2 variant has low GALT enzyme activity. The Duarte- 1 allele is associated with $\mathrm{N} 314 \mathrm{D}$ mutation in linkage disequilibrium with the L218L polymorphism. ${ }^{5}$ The Duarte-2 allele is associated with N314D mutation in linkage disequilibrium with three intronic polymorphisms IVS4nt-27 g- >c, IVS5nt-24 g- $>a$ and IVS5nt $+62 \mathrm{~g}->\mathrm{a}$ and a deletion c-119->-116delGTCA at the $5^{\prime}$ untranslated region. ${ }^{6,7}$ Duarte-1 type does not cause any clinical or biochemical abnormalities as the $\mathrm{L} 218 \mathrm{~L}$ polymorphism has been reported to increase the rate of translation of the N314D GALT protein. ${ }^{5}$ The deletion of the $5^{\prime}$ untranslated region-119->-116delGTCA in the GALT gene promotor region (Duarte-2 variant) causes a reduction in GALT gene transcription. ${ }^{8}$

In this report, we present GALT gene mutations in 56 cases of galactosemia from Turkey identified using DNA microarray resequencing. In addition, 105 healthy individuals were screened to determine the frequency of Duarte-1 and Duarte- 2 allelic variants in the Turkish population.

\footnotetext{
${ }^{1}$ Metabolism Unit, Department of Pediatrics, Faculty of Medicine, Hacettepe University, Ankara, Turkey; ${ }^{2}$ Institute of Child Health, Hacettepe University, Ankara, Turkey; ${ }^{3}$ Department of Molecular Biology, Hacettepe University, Ankara, Turkey and ${ }^{4}$ Department of Pediatrics, Faculty of Medicine, Osmangazi University, Eskisehir, Turkey Correspondence: Dr RK Özgül, Metabolism Unit, Department of Pediatrics, Faculty of Medicine, Institute of Child Health, Hacettepe University, Sıhhiye, Ankara 06100, Turkey. E-mail: rkozgul@hacettepe.edu.tr

Received 24 April 2013; revised 4 June 2013; accepted 1 July 2013; published online 8 August 2013
} 


\section{MATERIALS AND METHODS}

\section{Patients}

Fifty-six Turkish patients with galactosemia at Hacettepe University, Department of Pediatrics, Metabolism Unit, were included in the study for mutation detection in the GALT gene by using the resequencing microarray methodology. Written informed consent was taken from all participating individuals. Patients with classical galactosemia had typical symptoms such as failure to thrive, vomiting, hepatosplenomegaly and liver insufficiency. The diagnosis of galactosemia was suspected by the finding of a reducing substance, which does not react with glucose oxidase reagents, and by paper chromatographic identification of sugar.

\section{DNA isolation and PCR}

Genomic DNA was isolated from peripheral blood using ammonium acetate precipitation. The GALT gene was amplified as two fragments by long-range PCR using primers fragment-1F $5^{\prime}$-CACGGCCCTGCAGATTTTCC-3' ${ }^{\prime}$ fragment-1R $5^{\prime}$-CTTCATCACCCCCTCCCTGC-3' (PCR product length $1348 \mathrm{bp}$ ) and fragment-2F $5^{\prime}$-CAGCAAGCCCTACCTCTCG-3', fragment-2R 5'-AGTTG TAGCTGGAGCTATGC- $3^{\prime}$ (PCR product length $2878 \mathrm{bp}$ ). All primers were designed using Oligo Primer Analysis Software (Oligo Version 6.71, Molecular Biology Insights, Inc, Cascade, CO, USA). PCR reactions were performed for 32 cycles, with each cycle consisting of denaturation at $94^{\circ} \mathrm{C}$ for $10 \mathrm{~s}$, annealing at $60^{\circ} \mathrm{C}$ for $30 \mathrm{~s}$ and extension at $68^{\circ} \mathrm{C}$ for a minimum of $5 \mathrm{~min}$, with a final extension at $68^{\circ} \mathrm{C}$ for $15 \mathrm{~min}$.

\section{Mutation screening}

The microarray resequencing platform designed by our group for genetic screening of 10 different inherited metabolic diseases was used to detect all nucleotide substitutions, except for the insertion or deletion type of nucleotide changes. ${ }^{9} 10$ PCR products were purified with MinElute 96 UF PCR Purification (Qiagen, Hilden, Germany) and then the DNA concentration of each purified product was measured $\left(\mathrm{ng} \mu^{-1}\right.$ ) (NanoDrop Technologies, Wilmington, DE, USA). After quantitation, all equimolar amounts of PCR products were pooled to achieve even hybridization across the microarray. The PCR product mix was fragmented, end-labeled, hybridized, washed and stained. After completing the procedures, arrays were scanned using a GeneChip 300 Scanner (Affymetrix, Santa Clara, CA, USA), and chips were analyzed using GeneChip Sequencing Analysis Software 4.1 (GSEQ 4.1, Affymetrix). All identified nucleotide changes detected using the microarray resequencing method were confirmed by direct sequencing in both forward and reverse directions. The sequencing reaction was performed using BigDye Terminator Cycle Sequencing Version 3.1 (Applied Biosystems, Foster City, CA, USA). The ABI 3130 capillary electrophoresis system was used for automated sequencing with POP7 polymer (Applied Biosystems). Files were processed using sequencing analysis software. Hundred healthy individuals were screened by direct sequencing to further characterize novel mutations. The DNA mutation numbering is based on a complementary DNA reference sequence with nucleotide assumed as the 'a' of the ATG translation initiation codon.

\section{RESULTS}

In this study, we report mutation analysis in the GALT gene belonging to 56 patients represented with clinical findings for classical galactosemia and Duarte-1 type. Nucleotide substitutions in the GALT gene were detected using resequencing microarrays, except for the deletion or insertion type of nucleotide changes. The insertion/deletion type of mutations was detected using direct DNA sequencing. Mutation screening identified 109 of 112 mutant alleles in the GALT gene. Eleven types of mutations were detected in these patients, including nine recurrent mutations (c.425T > C; M142K, c.536G > A; G179D, c.563A $>$ G; Q188R, c.692G >A; R231H, c.855G $>$ T; K285N, c.881T >A; F294Y, c.958G >A; A320T, c.983G >A and; R328H, c. $940 \mathrm{~A}>\mathrm{G}$; E340*) and two novel mutations (c.772C $>$ G; R258G and c.928delG; G310fsX49). The novel G310fsX49 mutation was detected using direct DNA sequencing contrary to other mutations.
Table 1 Mutations detected in the GALT gene in 56 Turkish patients with galactosemia

\begin{tabular}{lcccc} 
Exon & Mutation & Coding effect & Allele frequency (\%) & Alleles detected \\
\hline 5 & c.425T $>$ A & M142K & 6.25 & 7 \\
6 & c.536G $>$ A & G179D & 0.89 & 1 \\
6 & c.563A $>$ G & Q188R & 55.35 & 62 \\
8 & c.692G $>$ A & R231H & 3.57 & 4 \\
8 & c.772C > G & R258G & 0.89 & 1 \\
9 & c.855G $>$ T & K285N & 3.57 & 4 \\
9 & c.881T $>$ A & F294Y & 6.25 & 7 \\
10 & c.928delG & G310fsX49 & 0.89 & 1 \\
10 & c.958G $>$ A & A320T & 7.14 & 8 \\
10 & c.983G $>$ A & R328H & 1.78 & 2 \\
10 & c.1018G > T & E340* & 10.71 & 12 \\
& & Total: & 97.29 & 109 \\
\hline
\end{tabular}

Abbreviation: GALT, galactose-1-phosphate uridyl transferase.

Forty-nine patients were homozygous and four patients had a compound heterozygous mutation. Only one mutant allele was identified in three patients. A mutation detection rate of $97.3 \%$ was achieved. Q188R was found to be the most frequent mutation in the present study with a frequency of $55.35 \%$. Q188R was detected in both alleles of 29 patients and in one allele of four patients. A320T (7.14\%), E340* $(10.71 \%)$ and $\mathrm{M} 142 \mathrm{~K}(6.25 \%)$ were detected as the second most common mutations. E340* was detected in six patients in a homozygous state together with N314D and L218L variations (Duarte-1 allele). The Duarte-1 allele was found with a frequency of $10.71 \%$. The Duarte-2 allele was not detected in this study.

Duarte-1 and Duarte-2 alleles were found to be present at a frequency of $2.3 \%$ and $1.4 \%$, respectively, in the screening of 105 healthy individuals from the Turkish population. All identified mutations and their allele frequencies are summarized in Table 1.

\section{DISCUSSION}

This study was conducted for genetic screening and characterization of the pathogenic mutation spectrum for the GALT gene in 56 cases of galactosemia (50 classic and 6 Duarte-1 type). Moreover, the frequencies of Duarte- 1 and Duarte- 2 alleles in the Turkish population were also determined. Surveys in different populations showed that the incidence of classical galactosemia varies between 1:30000 and $600000^{2,3,11}$ However, classical galactosemia was found more frequently in Turkey with an incidence of 1:23775.12

Worldwide, more than 250 mutations have been described in the GALT gene in various ethnic populations. We found 11 different genetic mutations, of which two were novel, including R258G and G310fsX49. In previous publications, detailed analyses are available on the effects of mutations on enzyme activity and protein structure. ${ }^{13,14}$ Here, we have only discussed the possible effects of novel mutations on the protein level described through this genetic screening study. One of them is the novel mutation R258G, which was found in a compound heterozygous state with Q188R. Maybe the R258 residue at the protein surface is involved in the formation of a salt bridge, thus altering the surface features of the molecule. The side chain of the glycine residue at the R258G mutation is very small as well. The mutation may have an effect on dimer assembly and stability or on the monomer stability. The G310fsX49 frameshift mutation results in a stop codon at amino acid position 49 after the deleted nucleotide. 
The most common mutation Q188R in the GALT gene was found in $55.35 \%$ of the Turkish population in the present study. Our results on the frequency of Q188R from this study are compatible with previously published studies on Turkish patients with galactosemia, which reported frequencies of $57 \%$ and $47 \%$, respectively. ${ }^{15,16}$

The Q188R mutation is the most common allele in all European countries and its frequency varies considerably according to the population. The frequency of the mutations (between 45 and $93.6 \%$ ) was reported to be as follows in different countries: Ireland, $93.6 \% ;{ }^{17}$ Great Britain, 77\%; ${ }^{3}$ Portugal, 57.8\%; ${ }^{18}$ The Netherlands, 58.5\%; ${ }^{19}$ Spain, 50\%; ${ }^{18}$ Germany, 69\%; ${ }^{20}$ Austria, 60\%; ${ }^{21}$ Poland, $51.3 \% ;{ }^{22}$ the Czech Republic and the Slovak Republic, 46\%; ${ }^{7}$ and Hungary, $45 \%{ }^{23}$ As in these European countries, it was also found to be the most common disease-causing mutation in the Turkish population, and presented data strengthen the observed pattern that the frequency of the Q188R mutation decreases from the west to the east and from the north to the south in the European continent. ${ }^{24}$

In the present study on the Turkish population, $\mathrm{K} 285 \mathrm{~N}$ is seen only in $3.57 \%$ of the population. The $\mathrm{K} 285 \mathrm{~N}$ mutation is the second most common mutation in most European countries. The frequency of this mutant allele varies from 19 to $33.8 \%$ in different European populations. ${ }^{7,20-23}$ In contrast to these high frequencies observed and reported above, some populations have a low allele frequency for this mutation, with distribution between 2.4 and $9.8 \%$ in European countries. ${ }^{18,19,25}$

These three mutant alleles, A320T (7.14\%), E340* (10.71\%) and M142K (6.25\%), are the second in terms of frequency in Turkish patients and are observed more commonly than in other populations. A320T and M142K were described as rare variants in other studies. ${ }^{26}$

The spectrum of mutations detected until now in GALT is as follows: M142K, G179D, Q188R, L218L, R231H, R258G, K285N, F294Y, N314D, G310fsX49, A320T, R328H and E340*; all of them represent the vast majority of disease-causing alleles in the Turkish population for galactosemia owing to GALT gene defects. The majority of disease-causing variations in GALT were defined, with results from the present study compatible with previous results. ${ }^{15,16}$

All mutations in the GALT gene are collected in exons 5, 6, 8, 9 and 10 of the gene. Considering all detected mutations, exons 6 and 10 account for $79 \%$ of all mutant alleles in our population. The higher frequency of mutations located within these exons in Turkish patients with galactosemia is an important observation. This knowledge would be helpful in molecular diagnostic studies for ranking alleles in terms of priority for mutation screening among galactosemia-causing pathogenic mutations, which is currently over 250 in number.

Interestingly, as already mentioned in the literature, we noticed that eight patients carrying the E340* mutation were of Turkish origin and carried this mutation in cis with $\mathrm{N} 314 \mathrm{D}$ and L218L. Gathof et al. ${ }^{27}$ first reported a Turkish boy with E340*, N314D and L218L. Schuster et $a .^{28}$ reported two Turkish siblings, and a different study by Seyrantepe et al. ${ }^{15}$ from Turkey indicated another Turkish patient with the same genotype; finally, in our study we identified six patients who carried the E340* mutation in cis with N314D and L218L.

The haplotype of E340*, N314D and L218L is most likely from a Turks ancestor. For drawing a precise conclusion, we should have identified the origin of the mutation; however, it is impossible to show an evidence-based approach for the founder effect of the haplotype in the Turkish population with currently available data obtained from a limited number of patients.

In this study, we have also evaluated the presence of Duarte variants in the Turkish population. A total of 105 healthy ( $n: 210$ alleles) individuals were screened for the presence of the Duarte variants of the GALT gene, and a total of eight alleles (3.8\%) were detected for N314D: five (2.3\%) were determined as a Duarte-1 variant and three $(1.4 \%)$ as a Duarte-2 variant. The frequency of the Duarte allele in Europe indicated considerable difference according to region. The frequency distribution is as follows: Northern Europe, 7.9\%; Eastern Europe, 5.3\%; Western Europe, 6.1\%; and Southern Europe, $2.0 \%$. African-American and Asian populations have lower frequency of the Duarte allele, $1.3 \%$ and $1.5 \%$, respectively. ${ }^{29}$ The frequency of the Duarte allele of our population is lower than the expected frequency (\%3.8) compared with Eastern Europe. If the E340* mutation had arisen from a common ancestor, it would be possible that this ancestor had also been a carrier of the Duarte-1 allele and that, therefore, the majority of Duarte alleles are seen together with E340*. However, the frequency of this allele in healthy individuals is lower, as they are not carrying the disease-causing haplotype for E340*. Another possible explanation for the diversity and differences in distribution among Duarte alleles, especially among the common mutations in the GALT gene, may be the geographical location of Turkey, which intercrosses two continents, Asia and Europe.

A high mutation detection rate of $97.3 \%$ was achieved by the application of resequencing microarray in this mutation screening study. This method provides a rapid and cost-effective approach for the screening of mutations in hereditary diseases. In comparison with available classical genetic screening methods, microarray resequencing can be considered a convenient method in terms of quickness, reproducibility and applicability for analysis of thousands of nucleotides in a single-array platform. This study is the first report about its application in genetic screening in classical galactosemia patients.

\section{CONFLICT OF INTEREST}

The authors declare no conflict of interest.

\section{ACKNOWLEDGEMENTS}

We thank the Hacettepe University DNA Bank for the biobanking. We are grateful to Esin Göksun for excellent technical assistance. This work was supported by State Planning Organisation from Turkey, Project number DPT2006K1206400603.

1 Leloir, L. F. Enzymatic transformation of uridine diphosphate glucose into galactose derivative. Arch. Biochem. Biophys. 33, 186-194 (1957).

2 Segal, S. \& Berry, G. T. in The Metabolic and Molecular Bases of Inherited Disease 7th edn (eds Scriver, C. R., Beaudet, A. L., Sly, W. S. \& Valle, D.) 967-1000 (McGraw-Hill Inc, New York, NY, USA, 1995)

3 Tyfield, L., Reichardt, J., Fridovich-Keil, J., Croke, D. T., Elsas, L. J. 2nd, Strobl, W. et al. Classical galactosemia and mutations at the galactose-1-phosphate uridyltransferase (GALT) gene. Hum. Mutat. 13, 417-430 (1999).

4 Schweitzer, S., Shin, Y., Jakobs, C. \& Brodehl, J. Long-term outcome in 134 patients with galactosemia. Eur. J. Pediatr. 152, 36-43 (1993).

5 Langley, S. D., Lai, K., Dembure, P. P., Hjelm, L. N. \& Elsas, L. J. Molecular basis for Duarte and Los Angeles variant galactosemia. Am. J. Hum. Genet. 60, 366-372 (1997).

6 Podskarbi, T., Kohlmetz, T., Gathof, B. S., Kleinlein, B., Bieger, W. P., Gresser, U. et al. Molecular characterization of Duarte-1 and Duarte-2 variants of galactose-1-phosphate uridyltransferase. J. Inherit. Metab. Dis. 19, 638-644 (1996).

7 Kozák, L., Francová, H., Pijácková, A., Macku, J., Stastná, S., Peskovová, K. et al. Presence of a deletion in the 5' upstream region of the GALT gene in Duarte (D2) alleles. J. Med. Genet. 36, 576-578 (1999).

8 Elsas, L. J., Lai, K., Saunders, C. J. \& Langley, S. D. Functional analysis of the human galactose-1-phosphate uridyltransferase promotor in Duarte and LA variant galactosemia. Mol. Genet. Metab. 72, 297-305 (2001).

9 Dursun, A., Özgül, R. K., Sivri, S., Tokatlı, A., Güzel, A., Mesci, L. et al. Mutation spectrum of fumarylacatoacetase gene and clinical aspects of tyrosinemia type 1 disease. JIMD Rep. 1, 17-21 (2011). 
10 Dündar, H., Özgül, R. K., Güzel-Ozantürk, A., Dursun, A., Sivri, S., Aliefendioğlu, D. et al. Microarray based mutational analysis of patients with methylmalonic academia: Identification of 10 novel mutations. Mol. Genet. Metab. 106, 419-423 (2012).

11 Elsas, L. J., Dembure, P. P., Langley, S., Paulk, E. M., Hjelm, L. N. \& Fridovich-Kell, J. A common mutation associated with the Duarte galactosemia allele. Am. J. Hum. Genet. 54, 1030-1036 (1994).

12 Demirkol, M., Baykal, T., Hüner, G., Șarbat, G., Ince, Z. \& Kurdoğlu, G. Newborn screening for biotinidase deficiency: A pilot study from İstanbul. in Diagnosis and Treatment of Inborn Errors of Metabolism: Contribution to an Equal Opportunity for Children in Asia and Europe (eds Demirkol, M. \& Shin, Y. S.) 23-26 (Ufuk Press, İstanbul, Turkey, 1996).

13 Facchiano, A. \& Marabotti, A. Analysis of galactosemia-linked mutations of GALT enzyme using a computational biology approach. Protein Eng. Des. Sel. 23, 103-113 (2010).

14 McCorvie, T. J. \& Timson, D. J. Structural and molecular biology of type I galactosemia IUBMB Life 63, 949-954 (2011).

15 Seyrantepe, V., Özgüç, M., Coşkun, T., Özalp, I. \& Reichardt, K. V. Identification of mutation in the galactose-1-phosphate uridyltransferase (GALT) gene in 16 Turkish patients with galactosemia, including a novel mutation of F294Y. Hum. Mutat. 13, 339 (1999).

16 Coşkun, T., Erkul, E., Seyrantepe, V., Özgüç, M., Tokatli, A. \& Özalp, İ. Mutation analysis of Turkish galactosemia patients. J. Inherit. Metab. Dis. 18, 368-369 (1995).

17 Murphy, M., McHugh, B., Tighe, O., Mayne, P., O'Neill, C., Naughten, E. et al. The genetic basis of transferase deficient galactosemia in Ireland and the population history of the Irish travellers. Eur. J. Hum. Genet. 7, 549-554 (1999).

18 Gort, L., Boleda, M. D., Tyfield, L., Vilarinho, L., Rivera, I., Cardoso, M. L. et al. Mutational spectrum of classical galactosemia in Spain and Portugal. J. Inherit. Metab. Dis. 29, 739-742 (2006).

19 Bosch, A. M., Ijlst, L., Oostheim, W., Mulders, J., Bakker, H. D., Wijburg, F. A. et al. Identification of novel mutations in classical galactosemia. Hum. Mutat. 25, 502 (2005)
20 Shin, Y. S., Zschocke, J., Das, A. M. \& Podskarbi, T. Molecular and biochemical basis for variants and deficiency forms of galactose-1-phosphate uridyltransferase. J. Inherit. Metab. Dis. 22, 327-329 (1999).

21 Greber-Platzer, S., Guldberg, P., Scheibenreiter, S., Item, C., Schuller, E., Patel, N. et al. Molecular heterogeneity of classical and Duarte galactosemia mutation analysis by denaturing gradient gel electrophoresis. Hum. Mutat. 10, 49-57 (1997).

22 Zekanowski, C., Radomyska, B. \& Bal, J. Molecular characterization of Polish patients with classical galactosemia. J. Inherit. Metab. Dis. 22, 679-682 (1999).

23 Milánkovics, I., Schuler, A., Kámory, E., Csókay, B., Fodor, F., Somogyi, C. et al. Molecular and clinical analysis of patients with classical and Duarte galactosemia in western Hungary. Wien Klin. Wochenschr 122, 95-102 (2010).

24 Holton, J. B., Walter, J. H. \& Tyrfield, L. A. in The Metabolic and Molecular Basis of Inherited Disease. 8th edn (eds Scriver, C. R., Beadet, A. L., Sly, W. S. \& Valle, D.) 1553-1583 (McGraw-Hill, New York, NY, USA, 2001).

25 Boutron, A., Marabotti, A., Facchiano, A., Cheillan, D., Zater, M., Oliveira, C. et al. Mutation spectrum in the French cohort of galactosemic patients and structura simulation of 27 novel missense variations. Mol. Genet. Metab. 107, 438-447 (2012).

26 Berry, G. T., Singh, R. H., Mazur, A. T., Guerrero, N., Kennedy, M. J., Chen, J. et al. Galactose breath testing distinguishes variant and severe galactose-1-phosphate uridyltransferase genotypes. Pediatr. Res. 48, 323-328 (2000).

27 Gathof, B. S., Sommer, M., Podskarbi, T., Reichardt, J., Braun, A., Gresser, U. et al. Characterization of two stop codon mutations in the galactose-I-phosphate uridyltransferase gene of three male galactosemic patients with severe clinical manifestation. Hum. Genet. 96, 721-725 (1995).

28 Schuster, V., Podskarbi, T., Ottensmeier, H., Haubner, M. \& Shin, Y. S. Simultaneous occurrence of various mutations and polymorphisms in cis and in trans of the galactose-1-phosphate uridyltransferase gene in a Turkish family with classical galactosemia. J. Mol. Med. 76, 715-719 (1998).

29 Suziki, M., West, C. \& Beuther, E. Large-scale molecular screening for galactosemia alleles in a pan-ethnic population. Hum. Genet. 109, 210-215 (2001). 